EM CENA， DEFICIÊNCIA: TECITURAS PROTÉTICAS ENTRE DISCURSOS E AUSENCIAS

Resumo

O presente artigo trata da discussão sobre as artes cênicas no Brasil, suas novas conceituações e abordagens, por meio da análise do contexto político e social da deficiência no campo da arte. Busca-se o aprofundamento das noções de inclusão, e cena, para além da ótica da superação da deficiência. O texto propõe-se ao debate sobre artistas deficientes no campo cultural e suas contribuições para mudanças estéticas.

Palavras-chave:

Artes Cênicas. Deficiência. Estética. 


\title{
EM CENA, DEFICIÊNCIA: TECITURAS PROTÉTICAS ENTRE DISCURSOS E AUSENCIAS
}

\author{
Ana Carolina Bezerra Teixeira (UFBa)'
}

\footnotetext{
${ }^{\mathrm{T}}$ Doutora em Artes Cênicas pelo PPGAC/Universidade Federal da Bahia (UFBA). Atuou como bailarina e diretora junto a Roda Viva Cia. de Dança em Natal (RN). É artista independente e cria intervenções e performances acerca do tema deficiência. Trabalhou como pesquisadora associada na Oberlin College em Ohio (EUA). É autora do livro 'Deficiência em Cena', lançado pela editora Ideia/PB (2011). E-mail: carolinateixeira25@yahoo. com.br.
}

Eu o corpo-lado fractal Escolhi o meio esquerdo de mim

A hipótese protética De uma estética amputada E qual (p)arte falta? Falta?

A cena artística brasileira refletiu diversas transformações políticas significativas nos últimos 35 anos, sobretudo relacionadas ao campo das lutas sociais, igualdade de direitos e acessibilidade universal. Transitar por estes territórios pode à primeira vista soar um tanto comum ou mesmo visível nos tempos atuais, mas é preciso pensar sobre como as transformações corporais ocorreram no campo da cena artística nacional e, em especial, nas artes cênicas.

As noções de eficiência foram predominantemente reforçadas no espaço cênico desde os modelos mais tradicionais 
da representação teatral ou da dança, em que prevaleciam os moldes corporais de rendimento, equivalência corporal, controle técnico ou mesmo exaustão física.

Neste sentido, busco a reflexão sobre como estes modelos assolaram a prática cênica e como ainda prevalecem associados a uma espécie de mimese que mantém os corpos criativos sujeitos à ideia da reprodução eficientis$\mathrm{ta}^{2}$ herdada das ações colonizadoras dos corpos considerados normais versus corpos anormais.

As novas significações empreendidas pelos estudos da performance no campo político, no campo artístico e no campo dos estudos da deficiência convergem para a discussão e urgente mudança trazida por artistas com algum tipo de deficiência ou experiência corporal excludente para o campo cênico.

Com o passar dos anos e com o meu envolvimento junto ao campo da arte e da Deficiência, pude vivenciar práticas variadas de contato com os corpos deficientes que, assim como eu viviam a experiência deste fenômeno em seu cotidiano social e artístico. Situação comum para quem vive uma deficiência é habitar estados de ausência física de membros, perdas visuais, sensações motoras ou de outros sentidos que podem mover para a criação de ações de apropriação corporal. Essas ações são naturalmente realizadas pela capacidade física de apropriação/adaptação de movimentos, seja por perda genética, ou por perda adquirida, o corpo humano preservou desde sempre a capacidade de desenvolver mecanismos de compreensão das experiências psicofísicas de cada indivíduo.

No caso da cena envolvendo corpos com algum tipo de deficiência, chamo a atenção para a realização de processos criativos que perpassaram por diversas fases, envolvendo períodos de experimentação, improvisação e aprofundamento das especificidades de cada artista e suas deficiências. No caso de minha experiência com companhias onde pude atuar como coreógrafa e preparadora corporal, o processo de observação-experimentação foi crucial para a prática de novas possibilidades cênicas, a partir do que eu tenho defendido como apropriação das impossibilidades no processo criativo de cada indivíduo.

O temo impossibilidade foi empreendido em minha dissertação de mestrado - defendida em 2010 pelo programa de pós-graduação em Artes Cênicas da UFBA (PPGAC) -, como sendo um lugar-conceito imposto ao deficiente pela sociedade, mas, em contraponto, um lugar compreendido na arte enquanto território onde o exercício das apropriações, experimentações e desistências vivenciadas com a experiência das ausências, incapacidades, dificuldades, tornam-se elementos essenciais no processo da criação.

A partir do entendimento de que a 'impossibilidade' é a força primeira e ulterior de criação do artista que tem ou não uma deficiência chego à reflexão de que é a partir dela enquanto rastro de criação que galgamos o processo cênico em sua completude.

No meu caso, danço a partir das relações que preciso criar entre um lado do corpo deficiente, e outro lado do corpo eficiente, são características de um AVC. A essa realidade, que do ponto de vista histórico-social-econômico é imposta a impossibilidade, acolho o enfrentamento a partir do conhecimento que vivencio neste mesmo lugar de negação e nulidade.

É preciso desmaterializar as práticas instituídas sobre o corpo, essa espécie de efeito catacrese, responsável por nomear/classificar, de forma arbitrária, os sujeitos como aquilo que devem ser perante a sociedade. No caso da Deficiência ${ }^{3}$, ela é a antítese de um projeto econômico de corpo estruturado pela ideologia da eficiência e, portanto, fincado num modelo que reproduz uma tradição de produção e manutenção de novas eficiências sejam estas econô-

\footnotetext{
${ }^{2}$ Termo por mim defendido em dissertação de mestrado defendida em 2010 pelo PPGAC Programa de Pós-Graduação em Artes Cênicas da UFBA.

${ }^{3}$ Importante destacar o uso do termo deficiência em minúscula como referência à condição patológica imposta aos corpos considerados imperfeitos durante a segunda metade do século XIX e o uso da Deficiência em maiúscula sinalizando a área de conhecimento emergente no campo das Ciências Humanas, inaugurada a partir da década de 1960.
} 
micas, sociais, políticas ou culturais.

Elegi como objeto-conceito para meu processo artístico e político enquanto performer a condição protética, que nos últimos seis anos tem norteado as minhas investigações sobre o fenômeno da deficiência na cena contemporânea. Originalmente, a palavra prótese, na gramática inglesa antiga, possuía o sentido de supressão das partes de um discurso incompleto e foi transformada - pela junção com a ciência - numa prática de substituição das partes perdidas do corpo, por volta da metade e final do século XIX.

Quando refletimos sobre a linguagem como sendo parte (substituta) do discurso escrito podemos compreender o seu sentido protético. Ou seja, como uma primeira prótese, a linguagem substitui velhas formas primitivas de comunicação tanto pela via oral como pela língua escrita. Ao mesmo tempo, a cultura protética corporificou-se e passou a substituir o projeto político corpo, a condição incapacitante imposta aos vitimados por doenças e guerra, substituindo membros ausentes por novos e pela manutenção da qualidade produtiva dos indivíduos.

A relação da prótese como elemento substituinte do corpo para repor o que chamamos popularmente de "toco" (DAVIS, 2013). Pode ser associado a tudo aquilo que é podado pela raiz, cortado, ou extirpado e de como esse termo também representou uma definição sobre as pessoas que perdiam partes ou funções de seu corpo. Hoje o elemento prótese assume um lugar claro de produção de novas eficiências, seja nas práticas visualizadas na mídia, ou mesmo enquanto recorrência econômica, geradora de produtos para um crescente mercado de consumo. Um mercado com estética própria e que reafirma o surgimento de novos empoderamentos corporais na busca não somente da substituição física, mas do alcance dos mesmos índices de eficiência e produção da sociedade.

Com efeito, a estética corporal padrão passa a ser visualizada a partir destas novas incorporações físico-sensoriais como aparelhos, próteses mamárias, sensores cardíacos, olhos artificiais ressignificando desta forma o modo como vemos e somos vistos em sociedade.

No território cênico, presenciamos uma migração político-corporal de indivíduos antes considerados invisíveis cenicamente e que passaram a utilizar o teatro, a dança, artes visuais e a performance como espaços para novas significações estéticas. Corpos negros, gordos, gays, não classificáveis e deficientes passaram a propor artisticamente para além do status quo eficientista para criar e recriar a partir de suas experiências corpo-invisibilizadas por processos sociais de estratificação e exclusão humanas.

Diversos personagens ao longo da história da literatura e do cinema foram caracterizados como deficientes, à exemplo de corpos desviantes como os apresentados em filmes como Um estranho no Ninho e Tempo de Despertar, onde pode-se localizar narrativas sobre as demarcações da loucura e do delírio. Em textos como Ricardo II podemos observar o drama de sua depressão em relação à uma conduta política conflitante que o leva à desistência e a uma profunda discussão sobre o humano. Já o capitão Ahab em Moby Dick, representa o típico arquétipo da tragédia física onde a deficiência chancela a condenação do corpo aleijado pelo ataque de uma baleia. Percebemos assim como a relação da deficiência com as demarcações físicas e mentais configuraram através dos tempos um imaginário político e estético sobre os corpos.

De fato, o caso das pessoas com algum tipo de deficiência destaca-se pelo lugar de dupla consciência ao qual estão submetidas em relação às perspectivas da sociedade eficientista. Refiro-me aos anseios sociais que correspondem às noções de produção, rendimento, habilidade, competências, resultado, dentre outras projeções. O fenômeno da Double Consciousness, já defendido por W.E.B. Du Bois em seu Livro The souls of black folk, enunciava o drama do negro norte americano ao ver-se condenado ao dilema da própria identidade racial na América, submetida ao olhar colonialista da alteridade branca, sob o constante espectro de viver entre duas realidades: 
É uma sensação peculiar essa dupla consciência, esse sentido de estar sempre olhando a si mesmo através dos olhos dos demais, de medir a alma com a trena de um mundo que olha com divertido desprezo e lástima. Sente-se sempre em uma dualidade, um americano, um negro: duas almas, dois pensamentos duas lutas irreconciliáveis, dois ideais em conflito em um corpo negro, cuja força tenaz evita que seja despedaçado. A história do negro americano é a história destes fatos, esta ânsia de alcançar a idade adulta, consciente de si mesmo, para fusionar seu duplo ego e um ego melhor e mais verdadeiro (DU BOIS, 1987, p. 2-3).

Esta teoria pode ser aproximada da realidade vivenciada por corpos considerados $f a$ lhos cotidianamente, ou seja, corpos que se sentem ora inseridos, ora excluídos, a depender das conveniências sociais em que se localizem. No território artístico, esta realidade também não poderia ser diferente, uma vez que, em definitivo, estes indivíduos artistas, cidadãos, criadores não estão incluídos nos setores fundamentais da produção cultural do país (instituições, grupos, mídia, produtores, gestores e mediadores da cena cultural). Esses artistas, em sua maioria, diluem-se em projetos pontuais e, muitas vezes, assumem apenas a função faber do processo artístico como atores e dançarinos, restando-lhes poucas alternativas onde possam atuar como diretores ou mesmo produtores/gestores da cena no país.

A presença desse corpo na cena artística brasileira inaugura-se entre o fim da década de 1980 e 1990, através da realização de festivais como o Festival Arte Sem Barreiras, promovido pela Funarte, e ações que envolviam a participação de ONGs e grupos terapêuticos. A dança e o teatro, nesse período, foram muito associados à reprodução de padrões cênicos já estabelecidos por grupos convencionais ao invés do desenvolvimento de uma práxis que considerasse as características corporais de cada artista, seus projetos e contribuições individuais para o processo de formatividade artística.

Pareyson (2007) já nos esclarece que a arte se dá no fazer e este mesmo fazer é fun- damental para entendermos o pensamento que antecede toda a criação. Esse mesmo aspecto manifesta-se claramente quando trabalhamos diante das complexas experiências com corpos autistas, cegos, amputados, surdos, paralisados e corpos que vivem as mais diversas experiências mentais. Está-se diante de saberes e visões sobre a própria experiência de si na sociedade e no processo artístico que estão diretamente imbricadas na construção estética da obra artística, em sua concepção, realização e consequentemente em sua recepção.

Mais de $14 \%$ da população brasileira possui alguma deficiência segundo dados do IBGE (2010), sem contar o processo de envelhecimento que permitirá a muitas pessoas o contato com esta realidade que ainda exclui milhares de cidadãos todos os dias em todo o mundo.

Pensar o fazer cênico dos corpos deficientes ou considerados abjetos fora desta realidade é relativizar o que representa a chancela 'deficiência' no país, é desconsiderar todo o mecanismo cultural, econômico e político imposto aos cidadãos cuja demarcação classificatória os excluiu dos principais setores da sociedade brasileira. $\mathrm{O}$ corpo do artista que vive a experiência da deficiência no Brasil, diferentemente de países como Inglaterra, França e Alemanha, é um exercício constante de resistência social.

O corpo deficiente segue desamparado política, jurídica e culturalmente; e esta compreensão é de suma importância para que possamos nos abster dosessencialismos e relativismos que ainda recaem sobre o fenômeno da deficiência no campo artístico nacional. Faz-se necessário reconhecer que esse corpo trouxe para a cena as realidades excludentes das arquiteturas, dos postos de saúde sem acesso, do transporte público inacessível e, sobremodo, as restrições das barreiras atitudinais ainda vigentes na sociedade brasileira.

Como fazer teatro, dançar, tocar música, pintar se a realidade excludente ainda impede que o artista-cidadão consiga locomover-se até mesmo na própria região onde vive? Discutir sobre essas barreiras é uma condição primordial para a compreensão da realidade pseudo- 
-inclusiva brasileira em todas as esferas públicas.

\section{A cena dos espaços clandestinos}

A experiência dos corpos considerados deficientes/falhos/abjetos revela uma apropriação das ausências e desdobra-se na condição de tornar-se artista, não como uma obrigatoriedade de respostas às questões sociais ou aos anseios do corpo social - que necessita de exemplos a seguir -, mas pelo direito à criação. Cabe reconhecer a fala que pode emergir de suas escolhas e desistências, de suas intenções/abandonos, de suas crises/sublimações, dos seus espasmos/dores, de seus desejos e repulsas.

O projeto político da arte contemporânea entre as décadas de 1950 até o final do século XX promoveu rupturas nos resíduos tradicionais impregnados no pensamento artístico moderno. Ou seja, mesmo com o advento de uma arte moderna de conceitos, de protestos, ou mesmo de uma negação velada, ainda mantinha-se cristalizado o modelo iluminista da eficiência racional do homem, condição que afetou sobremaneira as sociedades ocidentais se considerarmos a ideia do homem como corpo físico superior, valores da chamada ética-moral aristotélica, que não admitia cidadãos frágeis ou incapazes para a ação do pensamento. No campo da arte, mercados se alicerçaram sob esses modelos em função da manutenção de mercados estéticos específicos, assinados por grupos e artistas, aiatolás de seus próprios projetos/ escolas estéticas inabaláveis. Esvaziamentos das formas, reconhecimento das consideradas marginalizações artísticas, análise crítica, bioarte, performance política, hibridizações e o avanço das tecnologias consolidaram estéticas atemporais no que concerne às formas cada vez mais coletivas, interventoras da arte em nosso tempo.

A cena produzida por um corpo deficiente transita entre a especulação cotidiana do corpo hipervisibilizado por sua diferença ao mesmo tempo em que é vitimizado pela espetacularização de suas capacidades ou dificuldades. Um realidade dual que caracteriza um corpo e uma cidadania "meio termo" como afirmou David Le Breton (2009). Por conseguinte, passa a ocupar um espaço clandestino no território cênico por meio de concessões destinadas à sua inclusão. Defendo o termo "clandestinidade artística" no sentido de salientar que a aceitação desses corpos nas artes da cena é cristalizada por meio de um discurso inclusivista, onde o artista ainda é um indivíduo acolhido, mas que, todavia necessita sublimar, virtualizar ou superar os próprios limites do corpo. Ao sair do palco, o artista que vive as experiências aqui discutidas é atravessado por um mundo excludente que insiste em interpelar suas vontades, desejos e direitos.

Importante observarmos que o corpo cênico contemporâneo começa a caracterizar-se pela dissolução das fronteiras entre arte/ vida, sobretudo o teatro pós-dramático que passou a pensar as impossibilidades cênicas como uma forma de considerar também os acasos, os antagonismos e as situações percebidas como impedimento. As novas formas de perceber a cena envolvem a necessidade de aprofundar os interstícios criativos, as falhas e ecos ressonantes para a construção cênica. $\mathrm{O}$ artista passou a incorporar situações de crise na medida em que se reconhece na possibilidade de pensar seu próprio projeto estético, político e sua relação com a própria experiência em uma sociedade cada vez mais distinta e com processos diversos de identificação cultural.

O Teatro e a Performance compreendem campos artísticos que, a partir da década de 1990, passaram a incluir pessoas com algum tipo de deficiência, em especial, as práticas teatrais terapêuticas desenvolvidas em instituições manicomiais, prisionais, cuja função destinava-se à reabilitação e socialização.

A aplicação do teatro como prática educacional no Brasil pode ser destacada pelo trabalho de diretores como Augusto Boal. No que tange ao trabalho envolvendo pessoas com deficiência, as ações de formação são específicas, em especial durante o final da década de 1990 e início dos anos 2000. Cito, como exemplo, o grupo Teatro Novo do Rio de Janeiro fundado 
em 2005 pelo psicólogo Rubens Emerick que, já na década de 1990, participava de eventos inclusivos promovidos pela Funarte. A atuação do grupo destina-se até hoje à prática cênica como ferramenta inclusiva envolvendo pessoas com deficiência visual e síndrome de Down. Já o grupo carioca Teatro dos Sentidos destaca-se hoje como grupo pioneiro no Brasil na construção do que nomeiam como espetáculos acessíveis. A criação envolve desde intérpretes de língua brasileira de sinais, audiodescrições simultâneas, atores guias, bem como toda a estrutura física para receber qualquer tipo de espectador no espaço cênico caracterizado em seus espetáculos. Com sede no Rio de Janeiro, o grupo criado em 2000 desenvolve ações de formação, capacitação de atores e profissionais que tenham interesse em atuar na perspectiva acessível.

Em países como Argentina, a existência de instituições como o Teatro Ciego nos permite a reflexão sobre os modos de produção, execução e distribuição do produto teatral a partir de relações estéticas construídas com base na pesquisa, experimentação do corpo em sua experiência não visual, tanto de cegos como de pessoas não cegas. Criado em 1991, pelo terapeuta Ricardo Sued, a partir de técnicas de meditação no escuro, o Teatro Ciego influenciou boa parte das produções teatrais contemporâneas na Argentina e em países como o Brasil, a exemplo do grupo Teatro dos Sentidos.

Esses emergentes modos de apropriação cênico-estética possibilitam novas significações artísticas, novas semiologias para o campo teatral e, sobretudo, maior autonomia para artistas, criadores que começam a propor a partir e com suas próprias percepções cênicas.

Estar em cena, neste sentido, promoveu modificações nos cânones antes intocáveis no campo cênico, como a modificação dos elementos da linguagem teatral para a introdução de novos modelos representacionais como a narrativa falada, a utilização de recursos audiodescritivos, modificações na estrutura arquitetônica dos espaços, mudanças no perfil de público, que passou a admitir pessoas com algum tipo de deficiência ou redução de mobilidade.
Percebemos nas últimas décadas uma pequena mudança no paradigma estético que envolvia os modos de fazer-pensar a arte da cena apenas do ponto de vista da representação ou apresentação, para a partir de agora considerar a experiência cênica sinestésica, comunicacional, interativa que passou a incorporar novos modos de fruição e apreciação artísticos quando proporcionam ao espectador a experiência de ver-se através de outras sensibilidades e percepções antes desconhecidas.

No entanto, a atuação desta parcela significativa de criadores ainda se restringe às participações em grupos específicos ou propostas estéticas experimentais. Atuações pouco representativas, onde, em muitas situações, artistas sem nenhuma deficiência ocupam vagas para representarem personagens com algum tipo de deficiência, mesmo com a existência de profissionais que vivem em seu corpo esta característica.

Mesmo diante de corpos que podem, de alguma maneira, ser classificados como "singulares" em cena (TONEZZI, 2011), a prática teatral brasileira ainda se depara com um número restrito de artistas com algum tipo de deficiência. Por este motivo, venho, há alguns anos, me questionando sobre o quão contraditória parece ser uma cena que exige cada vez mais a precarização corporal, a exaustão, a transubstanciação do trabalho do ator, ao mesmo tempo que insiste em negar espaços para corpos que já habitam essas características perseguidas em cena.

Está-se diante de um dispositivo de relações estético-culturais ainda baseadas na funcionalização do corpo, em sua exotização ou na relevância de um discurso de superação através da arte, o que, por vezes, impossibilita o artista a criar e dialogar por meio de seus conhecimentos corporais na cena onde atua dentro e fora do espaço teatral.

O exemplo do ator francês Jean Claude Grenier pode ser aqui mencionado como uma exceção à realidade brasileira. Grenier foi conhecido como um dos maiores atores daquele país no que diz respeito à interpretação dos textos do dramaturgo irlandês Samuel Beckett, 
entre as décadas de 1980 e 1990 . O ator sofria de uma rara doença progressiva conhecida como Osteomielite, que atrofiou de forma severa o desenvolvimento de seus ossos. Grenier atuou com o Archaos Circus na França, e também no espetáculo Freaks, extraído do texto de Geneviève de Kermabon. Nesta peça ele representava um personagem deficiente físico (Titan), atração do famoso circo dos horrores. Se pensarmos que boa parte dos personagens construídos por Beckett atingiam o ápice da fragmentação social, física e moral, podemos achar conveniente a escolha por Grenier para protagonizar peças como Fim de Partida. No entanto, no caso desse artista, prevaleceu em sua atuação uma total autonomia, a mesma que o acompanhava em seu cotidiano pelas ruas de Paris e que pode ser vista no documentário La Longueur et la largeur du ciel, direção de Dominique Margot (1998).

Nota-se que, em relação a autonomia, aspecto amplamente discutido no documentário, o ator conseguiu atingir um reconhecimento entre a classe artística parisiense sem se exotizar pela função cênica. Ao invés disso, consolidou sua carreira entre grupos por onde passou ou mesmo em espetáculos solo onde pode colaborar como diretor.

Diferentemente do movimento artístico promovido pelo campo da Dança em meados da década de 1990, o teatro brasileiro permanece inacessível ao corpo deficiente por razões que ainda oscilam entre uma estética teatral terapêutica ou uma cena denominada inclusiva. Com efeito, é preciso o aprofundamento dos processos de composição, preparação que envolvem corpos com algum tipo de deficiência e o reconhecimento de suas experiências cognitivas, visuais, físicas e auditivas para além de uma ideia de tradução cênica. Deste modo, as justificações do discurso inclusivo passam a dar lugar ao entendimento das abordagens, dificuldades $\mathrm{e}$ efemeridades corporais passíveis de ocorrer em cena.
Como exemplo, podemos citar artistas com paralisia cerebral ou mesmo experiências mentais como a esquizofrenia. São processos de preparação corporal que devem considerar as temporalidades corporais de cada indivíduo, suas impermanências neuro-motoras, suas situações de crise ou mesmo sintomas como a desorientação devido à ingestão de medicamentos. Do mesmo modo, espasmos musculares, incontinências ou situações onde as marcações efetivadas em ensaios possam sofrer alterações no decorrer das apresentações. Essas impermanências estéticas são apropriadas pelo trabalho de grupo, onde todos assumem funções para além da ideia de "cuidadores", ao invés disso incorporam novos saberes ao processo criativo que aprofunda as especificidades corporais de cada integrante.

Como exemplo, posso mencionar a minha própria experiência junto à Roda Viva Cia. de Dança durante os onze anos em que atuei como bailarina e, ao final, como diretora artística. O uso de metodologias como o Contato Improvisação possibilitou a descoberta e o enfrentamento de diversas dificuldades que ali se anunciavam. A utilização da técnica representava, à época, a construção de estratégias e soluções para diversas barreiras corporais, como por exemplo: como dançar com espasmos, como solucionar a ausência de membros, de que maneira perceber o espaço sem a visão, dentre outros.

\section{Protéticas, performances e deficiência}

Em 2012 criei um trabalho intitulado "Poética Protética". Tratou-se de uma performance concebida após meu período de estudos de Mestrado na Universidade Federal da Bahia. $\mathrm{O}$ intuito era discutir como o elemento órtese ${ }^{4}$ poderia ser utilizado como metáfora para a discussão sobre a dicotomia presente entre exclusão e inclusão no cotidiano da pessoa com de-

\footnotetext{
${ }^{4}$ Prótese do grego $\pi \rho o ́ \sigma \theta \varepsilon \sigma ı \varsigma$ (adição): equipamento para substituição de partes ausentes no corpo (dentária, membros superiores e inferiores, ocular, auditiva). Órtese: equipamento para correção de partes do corpo afetadas por paralisias, síndromes, má formação, acidentes, lesões na coluna dentre outros (coletes, botas ortopédicas etc.).
} 
ficiência a partir de minha própria relação com a deficiência e com a utilização de aparelhos de correção física conhecidos como órteses. A partir daí construiria a ideia de uma poética-pessoal-protética que considerasse as relações de correção, pertencimento e ausência das capacidades físicas, justificando assim o uso do título "Poética Protética".

Esse trabalho foi realizado em formato de foto-performance e ainda está em desenvolvimento a partir das relações que investigo sobre a trilogia corpo-paisagem-deficiência com a inserção imagética do elemento órtese sob a perspectiva da Estética de Experiência, que posteriormente foi defendida em minha tese de doutoramento pelo Programa de Pós-Graduação em Artes Cênicas da UFBA em 2016. A estética da experiência com a deficiência foi assim definida:

[...] assumir um discurso estético sobre ou a partir das deficiências deve ser uma escolha legítima do artista ou grupo e não uma preocupação institucionalizada pelas estruturas estéticas da arte-forma. A deficiência não pode ser transformada em uma 'comoditie' artística tradicional. É preciso deixar claro que a deficiência sempre será o grande leitmotiv do artista em cena, porque está nele, é parte de sua realidade social, é uma narrativa orgânica construída em territórios de experiência com a exclusão e a inclusão. Porém, vivemos em sociedades de produção de eficiências, de economias de sentido e justificação e seguimos imersos nessa espécie de padronagem do corpo, rumo ao projeto de equidade (TEIXEIRA, 2016, p. 182).

Durante a pesquisa, pude investigar os processos realizados na cena da dança e da performance no Brasil e nos EUA, envolvendo artistas com algum tipo de deficiência que atuavam de forma independente. Para isso, efetuei investigações com teóricos como Ann Cooper Albright e Petra Kuppers, ativistas como Scott Rains, artistas como a Axis Co Dance, os performers Bill Shanon e Alice Sheppard e o grupo Dandelion Dancetheater, a Roda Viva Cia de Dança e o artista Edu O. A pesquisa, institucio- nalmente catalogada como área da Dança, foi mais além e mostrou-se um documento vasto sobre as diversas reverberações políticas, históricas e sociais sobre o fenômeno da Deficiência.

$\mathrm{O}$ intuito foi aprofundar e estender o entendimento sobre o papel do trabalho artístico, dos movimentos sociais de luta e das construções teóricas sobre a deficiência a partir das vozes de pessoas que vivem ou viveram essa experiência no corpo e suas apropriações desta no campo artístico. Assim, longe de se tratar de uma tese reivindicativa, o trabalho revelou-se um prisma norteador para a discussão sobre cena, estar em cena dentro e fora do substrato social e em contextos completamente diversos como o do Brasil e dos Estados Unidos.

Um dos trabalhos mais relevantes foi o do grupo Tiresias da Universidade de Michigan nos EUA, sob direção da professora e performer Petra Kuppers. O trabalho desse grupo consistia em operar, a partir da performance, com textos, poesias, crônicas que envolvessem o tema da deficiência em suas diversas abordagens. Desde o erotismo, saúde, esportes, política até mesmo ficção a científica, tudo era utilizado como material para a composição de monólogos e leituras dramáticas. Assim, o tema Deficiência alcançava outra dimensão cênica, quando consideradas as falas, as mobilidades, as dores e as sequelas envolvidas em cada composição. Apesar do pouco contato com o grupo, pude ter acesso a materiais como livros e vídeos produzidos pelo laboratório cênico junto à universidade.

A especulação, a espetacularização e a exploração desse emergente nicho da economia cênica mundial passou a ser foco para novas reflexões, críticas e conciliações no âmbito da arte, produção, difusão e cultura da acessibilidade, temas tão atuais do campo das artes cênicas. A ditadura do olhar especulador ou do que os pesquisadores americanos denominam como gaze, foi responsável por demarcações cruciais que ainda atuam de forma sutil na vida de pessoas com algum tipo de deficiência. Aquele que olha, como olha e o que socialmente olha refletem diretamente sobre os modos de atuação e cons- 
trução do status quo deficiente. Neste sentido, urge a mudança dos posicionamentos artísticos de reparação ou relativização das deficiências com a utilização de termos como "somos iguais", quando na verdade estamos diante de processos de silenciamento e invisibilizações que há séculos se utilizam de extrema violência e demarcação.

Portanto, considerar em nossa cena contemporânea que os corpos se justifiquem cenicamente por meio de um falso paternalismo artístico é colaborar para a manutenção de novas formas de exclusão e abjetificação através da arte. Assim, a cultura protética da eficiência corporal se mantém por meio das regulações deste corpo, bem como da criação de concessões cênicas ao invés da garantia do direito à criação, autonomia e produção de conhecimento por parte dos corpos que vivem a experiência chamada da diferença no corpo. O artista que tem algum tipo de deficiência rompe paradigmas e discursos pelo simples fato de sua existência. A sua aparição cênica é a anti-norma da eficiência da tradição espetacular; é a reinvenção dos cânones de eficiência técnica, dramatúrgica. $\mathrm{O}$ Narciso às avessas aprendeu a quebrar os espelhos partidos da história para lançar-se rumo à construção de outras novas possibilidades artísticas e emancipatórias. 


\section{REFERÊNCIAS}

DAVIS, Lennard J. The End of Normal: identity in a biocultural era. Ann Arbor: Michigan University Press, 2013.

DU BOIS, W.E.B. The Souls of Black Folk. Separata de DU BOIS, W.E.B. W.E.B. Du Bois Writings. New York: Library of America, 1987.

LE BRETON, David. Sociologia do Corpo. Petrópolis: Vozes, 2007.

PAREYSON, Luigi. Os Problemas da Estética. São Paulo: Martins Fontes, 1997.

TEIXEIRA, Ana Carolina Bezerra. A Estética da Experiência: trajetórias do corpo deficiente na cena da dança contemporânea do Brasil e dos Estados Unidos. 2016. 239 f. Tese (Doutorado em Artes Cênicas) - Escola de Dança/Escola de Teatro, Universidade Federal da Bahia, Salvador, BA, 2016.

TONEZZI, José. A Cena Contaminada. São Paulo: Perspectiva, 2011.

BIBLIOTHEQUE NACIONALE DE FRANCE. Jean Claude Grenier. Freaks. 1988. Disponível em: http://data.bnf.fr/39497721/freaks_spectacle_1988/. Acesso em: 27 de julho de 2018. 


\begin{abstract}
This article discusses performing arts in Brazil, specifically its new conceptualizations and approaches, by means of an analysis of the political and social context of disability in the field of art. It intends to deepen the notions of inclusion and performing arts, and going beyond the disability overcoming perspective. The paper will contribute to the debate about disabled artists in the cultural field and their contributions to aesthetical transformations.
\end{abstract}

\title{
Keywords
}

Performing Arts. Disability. Aesthetics. 